\title{
Correction to: Increased prevalence of cerebral microbleeds in patients with low left ventricular systolic function
}

\author{
Tomohiko Watanabe ${ }^{1} \cdot$ Yumiko Kanzaki $^{1}$ (1) Yohei Yamauchi $^{1} \cdot$ Takahide $_{\text {Ito }}{ }^{1} \cdot$ Yusuke Nishida $^{1}$. \\ Kenichiro Yamamura ${ }^{2} \cdot$ Tsuyoshi Komori $^{2} \cdot$ Koichi Sohmiya $^{1} \cdot$ Masaaki Hoshiga ${ }^{1}$
}

Published online: 4 March 2020

(c) Springer Japan KK, part of Springer Nature 2020

\section{Correction to: Heart and Vessels (2020) 35:384-390 https://doi.org/10.1007/s00380-019-01503-0}

In the original publication of the article, under the results section, the following sentence "Of 118 patients with CMBs, an average number of CMBs were $2.6 \pm 3.2,55$ patients (47\%) in lobar locations, 84 patients $(71 \%)$ in deep or infratentorial locations, and 26 patients $(22 \%)$ in both locations" was published incorrectly.

The correct sentence should read as "Of 118 patients with $\mathrm{CMBs}$, an average number of $\mathrm{CMBs}$ were $2.6 \pm 3.2$, 58 patients $(49 \%)$ in lobar locations, 86 patients $(73 \%)$ in deep or infratentorial locations, and 26 patients $(22 \%)$ in both locations".
Publisher's Note Springer Nature remains neutral with regard to jurisdictional claims in published maps and institutional affiliations.

The original article can be found online at https://doi.org/10.1007/ s00380-019-01503-0.

Yumiko Kanzaki

in3089@osaka-med.ac.jp

1 Department of Cardiology, Osaka Medical College, 2-7

Daigaku-machi, Takatsuki 569-8686, Japan

2 Department of Radiology, Osaka Medical College, Takatsuki, Japan 